\title{
Dehiscencia de sutura en gastroplastia endocoscópica
}

Suture dehiscence in endocoscopic gastroplasty

Valdemir José Alegre Salles ${ }^{1}$

ORCID https://orcid.org/0000-0003-4955-7160

DOI 10.31837/cir.urug/5.2.14

Gustavo Simões de Araújo Alegre Salles 2

ORCID https://orcid.org/0000-0003-3450-3469

1sabela Simões de Araújo Alegre Salles 3

ORCID https://orcid.org/0000-0003-4573-2611

Victor Dias Chaves ${ }^{4}$

ORCID https://orcid.org/0000-0002-4708-9933

Recibido: 16 de marzo de 2021

Aceptado: 30 de junio de 2021

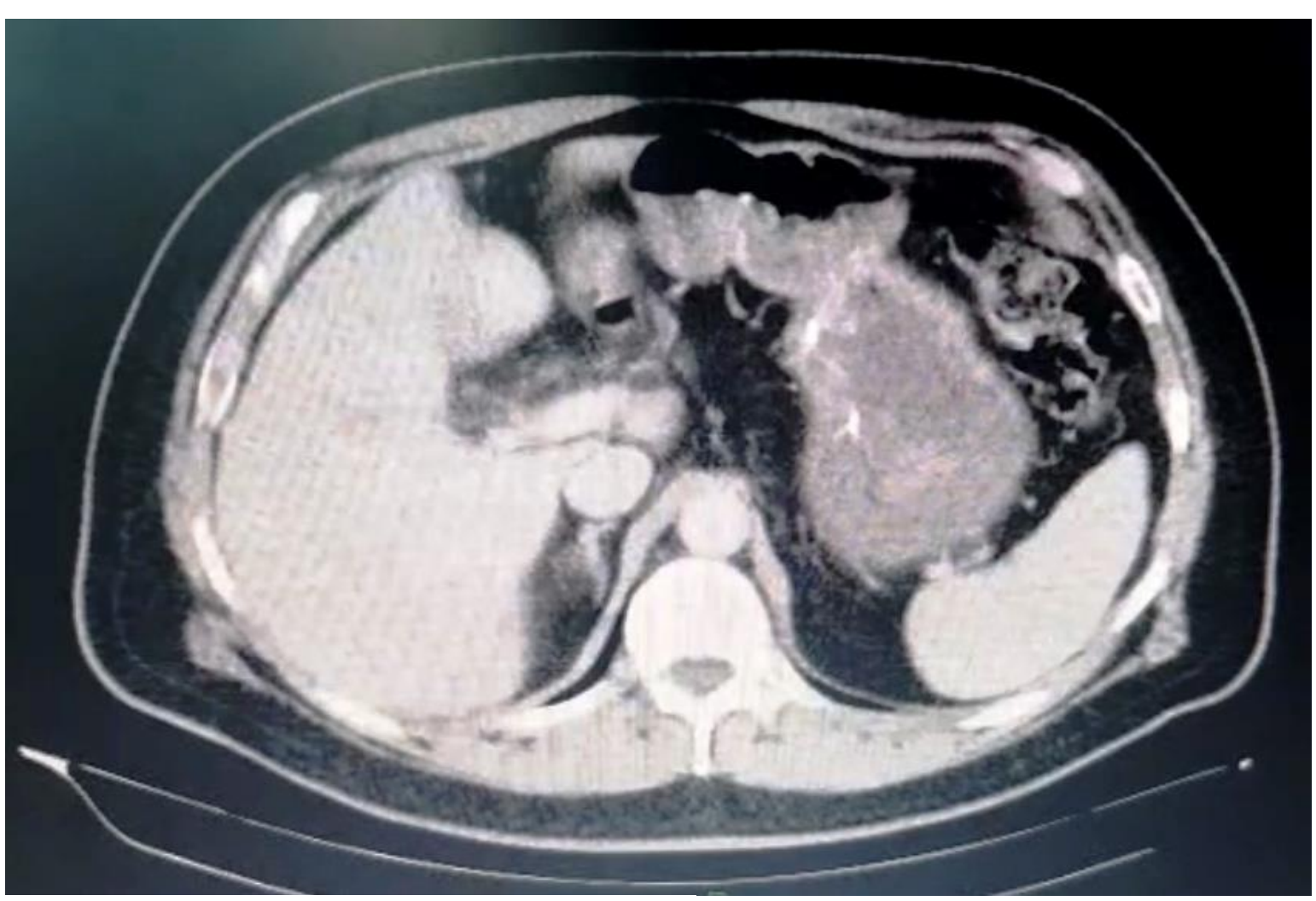

Figura 1. TC abdominal que muestra cámara gástrica normal.

${ }^{1}$ Profesor Asistent-Doctor, Universidad de Taubaté, San Pablo, Brasil valdemirsalles1962@gmail.com

${ }^{2}$ Estudiante de Nutrición, Universidad San Camilo, San Pablo, Brasil.

${ }^{3}$ Estudiante de Medicina, Centro Universitario de Volta Redonda - UNIFOA, Rio de Janeiro, Brasil

${ }^{4}$ Residente de Cirugía General, Universidad de Taubaté, San Pablo, Brasil 
Hombre de 56 años, sometido a gastroplastia endoscópica hace 8 meses, evolucionando con la recuperación de peso. El paciente presentaba como comorbilidades: una dislipidemia, hipertensión arterial sistémica y apnea del sueño, antes del procedimiento tenía una BMI de $38,74 \mathrm{Kg} / \mathrm{m}^{2}$, con un peso estimado de $122 \mathrm{~kg}$. El aumento de peso de $14 \mathrm{~kg}$ fue más evidente en los últimos 2 meses. Sometido a una tomografía computarizada abdominal mostró una cámara gástrica preservada (Figura 1).

Durante el examen de la endoscopía se encontró dehiscencia de la sutura endoscópica (figuras 2 y 3).

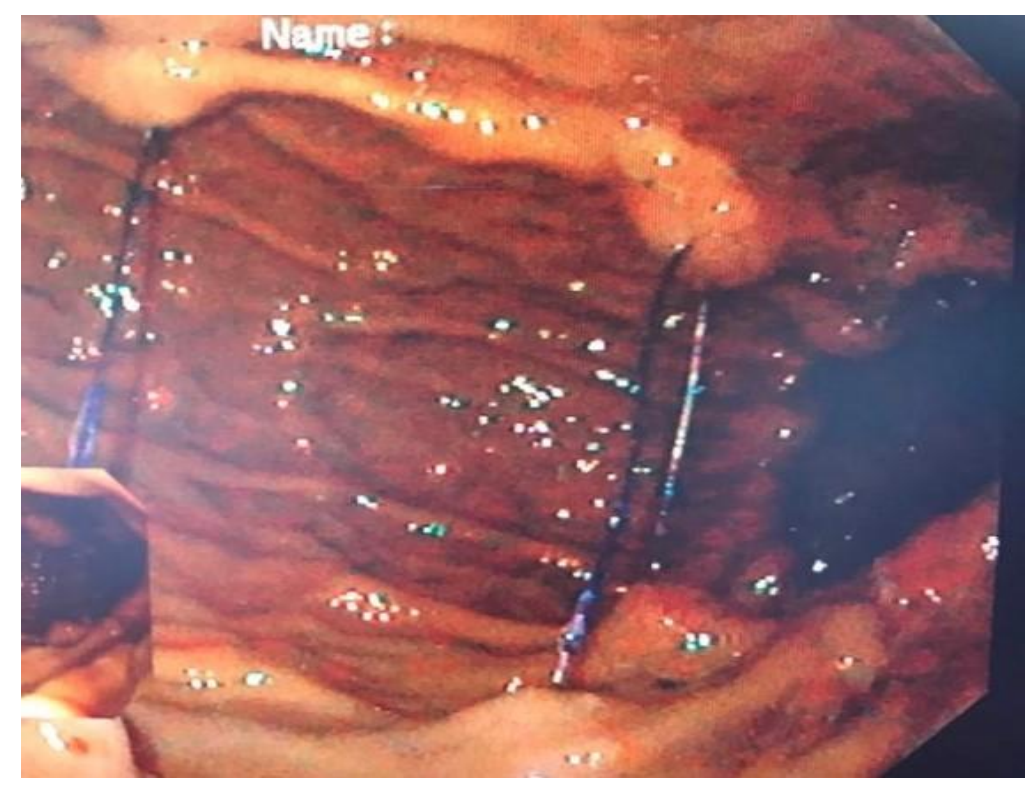

Figura 2.

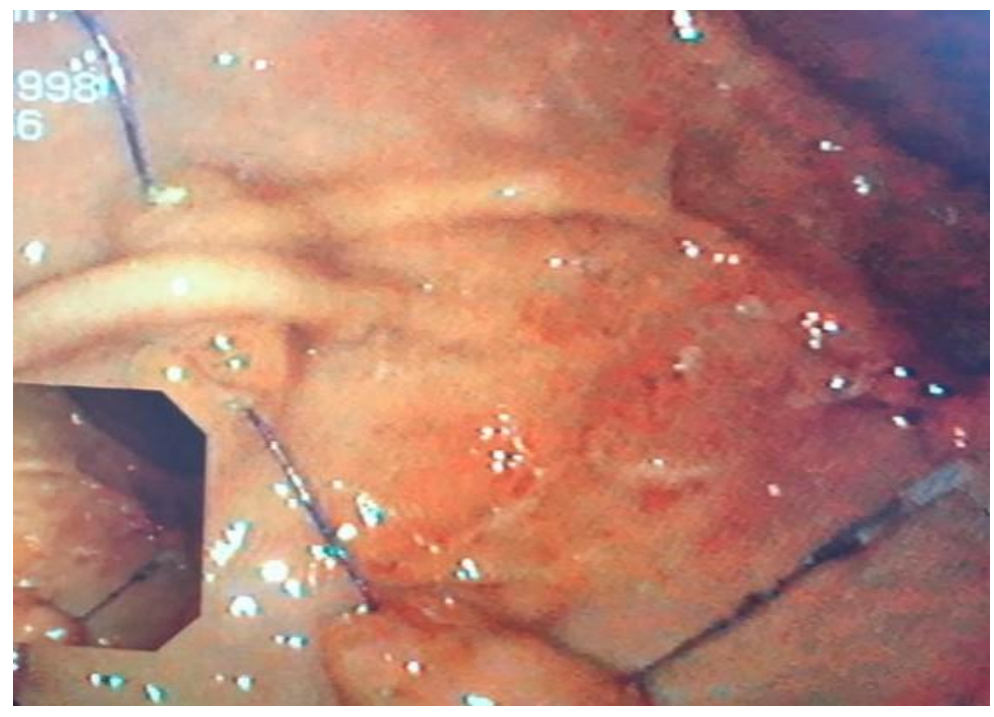

Figura 3.

Figuras 2 y 3 . Imagen endoscópica con pérdida completa de gastroplastia. 
Aunque de la apertura de los puntos en la pared gástrica, existe una restricción de la distensión de la cámara gástrica, puede ser responsable de la saciedad temprana, lo que hace que el paciente mantenga la pérdida de peso. La técnica endoscópica consiste en un endoscopio que se inserta a través de la cavidad bucal hasta el estómago, donde se despliega una serie de suturas.

Las suturas se colocan comenzando desde la parte pilórica y luego moviéndose gradualmente hacia el fondo gástrico ${ }^{1}$. En la técnica de gastroplastia se utiliza una aguja curva e hilo de polipropileno 20 , rodeando la pared gástrica con una profundidad de $15 \mathrm{~mm}$. Las suturas ceñidas crean una línea de pliegues en la pared del estómago, reduciendo radicalmente el volumen gástrico ${ }^{2}$.

\section{Referencias}

1 - Ferrer-Márquez M; Ferrer-Ayza M; Rubio-Gil F; Torrente-Sánchez MJ; Martínez Amo-Gámez A. Revisión quirúrgica bariátrica tras gastroplastia vertical endoscópica. / [Revision bariatric surgery after endoscopic sleeve gastroplasty. Cir Cir. 2017;85(5):428-31. doi: 10.1016/j.circir.2016.05.011

2 - Sowier A., Pyda P., Borucka A-M., Sowier S., Białecki J., Kapturzak J., Wójtowicz S.; Initial experience with endoscopic sleeve gastroplasty in Poland; Pol Przegl Chir 2018: 90 (2):16-22 doi: 10.5604/01.3001.0011.7488 